\title{
Resistance of Vocationalism as Education for Entrepreneurship in the Secondary School System in Zimbabwe
}

\author{
Wilard Nyathi ${ }^{1 *}$, Caxton Shonhiwa ${ }^{2}$ \\ ${ }^{1}$ Dean: Faculty of Education: AMADI University: Swaziland \\ ${ }^{2}$ Senior Lecturer: Faculty of Commerce: Zimbabwe Open University
}

*Corresponding Author: Wilard Nyathi, Dean: Faculty of Education: AMADI University: Swaziland

\begin{abstract}
This paper discusses attempts at vocationalism in the secondary school system in postindependence as a way of producing school products who can create jobs for themselves and others in Zimbabwe with specific reference to secondary schools. During colonial times in Zimbabwe, education for whites was compulsory and heavily subsidized by the state. For Africans, education was voluntary and parents had to pay their own school fees. That reduced access to schooling for many children of school-going age. Besides the financial constraints, in African education there were legal bottlenecks which inhibited the expansion of African education. Because of the financial constraints and distance from the nearest school, attrition rates in African schools were very high. The white system of education had very low attrition rates. Furthermore, during the liberation war, many students left their schools to take part in that protracted struggle. When the war was over, these gallant fighters wanted to continue with their education which had been disrupted. In addition to the ex-combatants, there were thousands of young Zimbabweans who were in refugee camps in various neighboring countries. Therefore, it came as no surprise when the new government prioritized the provision of education to all those who wanted it. Despite the above efforts at democratizing education the extent and rate of growth of unemployment in Zimbabwe is quite high among young school leavers. As a result of the above situation, schools are now being subjected to a barrage of criticism. Most major stakeholders appear to be unanimous in condemning the mainly academic curriculum. There have been attempts to vocationalise the system to escape the criticism it is facing.
\end{abstract}

Key terms: Post independence, vocationalise, secondary school, African, academic curriculum

\section{INTRODUCTION}

In 1999, the President of Zimbabwe appointed a twelve-member commission of inquiry into Education and training in Zimbabwe. The commission which was led by Professor Nziramasanga, comprised of prominent educationists, administrators, industrialists and parents undertook extensive and wide ranging consultations with a wide cross section of stakeholders. They examined the nature and status of education and training in Zimbabwe among other things and came up with a number of recommendations. One of the conspicuous recommendations that the committee put forward was that the secondary school curriculum had to be vocationalised. The Zimbabwean school curriculum was described as being too academic and only relevant to about twenty percent of the learner population (Nziramasanga, 1999). The school system produced school leavers whose prime objective was to look for jobs which unfortunately were scarce in the market. Thus, it was necessary that this curriculum had to be modified and made relevant for all learners.

\section{LITERATURE REVIEW}

\subsection{Vocationalism in the Secondary School System in Zimbabwe}

Swatz (1992) carried out an investigation about secondary school certification in Zimbabwe for the period 1979-1990. This enquiry had two objectives: first to examine briefly the nature of and changes in secondary school certification (SSC) since independence, with particular emphasis on the attempts to introduce a more vocationally oriented curriculum, and second, to evaluate the impact of these reforms via a discussion of the relationship between certification and the economy in postindependence Zimbabwe. 
In examining Secondary Certification in Zimbabwe, Swartz advanced two broad arguments. The first is that while attempts to revise radically the academic orientation of qualifications through the introduction of a form of "vocationalism" in secondary schools have been at best piecemeal, at worst contradictory, it is also not altogether clear that vocational education is necessarily the best alternative to the academic learning system. The second is that for radical reform in education to be effective as measured by greater employability, equity and economic democratization it has to be accompanied by changes in the operational logics and relations in the economy; that radical change and impact of education on society depends as much on conditions in the socio-economic and political spheres as on changes in the school.

\subsection{The Policy of Education with Production (EWP)}

In opposition to the colonial education doctrines, the ruling party in Zimbabwe constructed its own vision of a radically new philosophy of education. The thrust of this vision is contained in the notion of Education with Production. Siyakwazi (1984"109) and Treffgame (1989:9) says:

Education with production (EWP) should not be seen as an activity or a series of activities. Rather it is a philosophy of education. It is not limited to practical subjects such as agriculture, home economics, but to all subjects. It brings together theory and practice, and seeks to make school experience meaningful and worthwhile in terms of real-life activities outside of school.

If the logic and thrust of EWP can be summarised in relation to a new concept of education and certification, then at least three goals stand out:

- Economic - to create a dynamic link between the world of work and school through mass development and the democratisation of education opportunities talents and skills, and thus enhance the productivity and socialisation of labour (Chung and Ngara, 1985).

- Technical - to reconstruct the field of knowledge in the school, the "text" and popular consciousness in ways which transcend the dichotomies of theoretical vs practical, academic vs vocational and mental vs manual labour; and

- Political and ideological - to (re) discover, promote and develop knowledge, values, traditions and so on, which could be incorporated into an emergent national and continental identity (Treffgarne, 1989).

Although the government committed itself to extending and deepening the philosophy of EWp as a model for a new education dispensation, as a concrete policy it has mainly been applied to a small number of "new" vocational schools (eight by 1991) run by the Zimbabwe Foundation for Education with Production which were meant to be pilot schools (ZIMFEP). This means that the mainstream school system which caters for the overwhelming majority of students and in which the bulk of state resources in education is spent, has largely orbited outside the core of EWP thinking and policymaking.

Although the government has been careful to admit that EWP for the mainstream secondary schools has not been a realistic possibility in the first decade of independence for reasons such as lack of resources and political opposition from churches like Roman Catholic Church and other civil society groups, the role played by teachers' attitudes in sabotaging the policy has not been adequately investigated (NRZ, 1990:16).

The fundamental reason for instituting this investigation was primarily to find out he perceptions of teachers towards practical subjects, a gap knowledge which needs to be closed in order to avoid further policy implementation failures in education.

\subsection{New Vocationalism}

The notion of new vocationalism in contrast to the earlier colonial model of F2 schools, has often been used in official and education narratives, as a variant of EWP philosophy for secondary education policies. It is a loose term referring to an intermediary type of education, something between job-specific and often narrowly focused vocational training, usually associated with companies or specialized institutions, and university focused general academic education (Chung and Ngara, 1985:106-9), Maravanyika, 1989; Moyo, 1985). 
"Strictly vocational education has never been seriously considered for secondary schools in Zimbabwe because of the broader purpose of education, the gargantuan costs involved in such a project and political opposition" Swartz (1992"119). Training for very specific industrial or commercial fields such as lathe-operators, or spray painters is, as in most countries researched for specialized state, quasi-state and private colleges (in Harare, Bulawayo and other towns) and several apprenticeship programmes (carried out by on-the-job schemes and technical colleges.

"New vocationalism, on the other hand, although lacking any systematic conceptualization, seems to embrace the incorporation of practical skills-specific education into the existing essentially academic school curriculum" (Chung and Ngara, 1985).

\section{MeThOdOLOGY}

The study employed the secondary research methodology or desk top research. Secondary research or desk research is a research method that involves using already existing data. Existing data is summarized and collated to increase the overall effectiveness of research. Secondary research includes research material published in research reports and similar documents. These documents can be made available by public libraries, websites, data obtained from already filled in surveys etc. Some government and non-government agencies also store data, that can be used for research purposes and can be retrieved from them. Secondary research is much more cost-effective than primary research, as it makes use of already existing data, unlike primary research where data is collected first hand by organizations or businesses or they can employ a third party to collect data on their behalf. The researcher used the secondary research approach fully aware of its strengths and weaknesses which are briefly discussed below.

\subsection{Advantages of Secondary Research}

1. Most information is secondary research is readily available. There are many sources from which relevant data can be collected and used, unlike primary research, where data needs to collect from scratch.

2. This is a less expensive and less time-consuming process as data required is easily available and doesn't cost much if extracted from authentic sources. A minimum expenditure is associated to obtain data.

3. The data that is collected through secondary research, gives organizations or businesses an idea about the effectiveness of primary research. Hence, organizations or businesses can form a hypothesis and evaluate cost of conducting primary research.

4. Secondary research is quicker to conduct because of availability of data. Secondary research can be completed within a few weeks depending on the objective of businesses or scale of data needed.

\subsection{Disadvantages of Secondary Research}

1. Although data is readily available, credibility evaluation must be performed to understand the authenticity of the information available.

2. Not all secondary data resources offer the latest reports and statistics. Even when the data is accurate, it may not be updated enough to accommodate recent timelines.

3. Secondary research derives its conclusion from collective primary research data. The success of your research will depend, to a greater extent, on the quality of research already conducted by primary research.

\subsection{Findings and Discussion}

\subsubsection{Certification, Education and Reform}

The researcher found that the way qualifications are recognized, controlled and administered - which is certification, has always been the site of power of the career bureaucrat, the specialist, the education planner, the politician and last but not least the employers. This assertion was also confirmed by found to be applicable in Zimbabwe by Swartz (1992). Swartz (1992) found that certification in Zimbabwe also shapes and conditions the value attached to education, what skills are deemed important, what knowledge is perceived as meaningful and desirable and the potential it offers in the 
quest for material fulfillment and how it either provides or denies access to institutions of public or private life.

\subsubsection{The Stubborn Persistence of Academicism}

The study revealed that at least four broad institutional elements existed each operating from a different angle in relation to the school, and these elements seemed to have a decisive influence on the persistence of academic education. These elements were; the role of the education bureaucracy and state planners, the influence of the "university" in the structural organization of schools popular and professional expectations and the operational logic and expectations of the economic regime.

The role of the bureaucracy in sustaining the academic culture is both indirect and direct. Its indirect influence lies in the tendency of the state bureaucracy itself as a major employer, particularly in the Civil Service, local government and education, to retain hiring practices that require traditional academic qualifications, in many cases five Ordinary Level subjects including English, Mathematics and Science. As the Civil Service has increasingly been seen as a source of stable, relatively highincome employment for many blacks in Zimbabwe over the last ten years, it is not surprising that many students actually prefer academic to more restrictive vocational type subjects. Thus, in Zimbabwe as in most Third World countries where radical change and the proliferation of a massive state bureaucracy are directly connected, the state's role as a major employer has, according to Swartz (1992:123) "paradoxically reinforced the very model of education it considered to be problematic".

The more direct influence of the state bureaucracy can be seen in the role played by state planners in education. First, as in pre-independence times, decision making in the crucial areas of curriculum construction and examination design has remained in the hands of state planners, administrators, "experts" and career politicians. Thus, the Curriculum Development Unit (CDU) set up by the Ministry of Education in the 1980s is responsible for the administration of and is itself involved in the design of new texts for schools Jansen (1991"108). Unlike the case of Nicaragua (Anorve (1986:89) "there seems to be remarkably little if any popular participation in the writing, description and vetting of new material even from the organized teaching community.

Second, most of the curriculum specialists are themselves products of an essentially universityoriented, academic learning system and many are not experienced in the conceptualization, planning, design and implementation of vocational oriented curricula (Naggard, 1989:25). Third, there is a discernible trend for material, particularly examination papers to be designed according to previous formats.

The academic culture is also perpetuated by the continued role of "the university: (used here in a generic sense) in the structural organization of schools. The school system in Zimbabwe still retains its "upward-looking focus: the main core of subjects for ZJC and O' Level are still styled in a manner that seems to gear students for entry to 'A' Level and eventually university studies" (Sachikonye, (1970:77). And the examinations, as in the case of most academic type education systems elsewhere in the world, still reflect mainly university-based knowledge and test general rather than specified skills, even in the context of a glaring "mismatch between the academically oriented education possessed by thousands of Ordinary and Advanced Level graduates and the specific technical skills required by industry" (Sachikonye, (1990:76).

A third factor cited by Swart (1992) that influences the stubborn persistence of the academic model seems to be the popular and professional expectations of what success at school entails. This was clear from the public outcry at the ' $\mathrm{O}$ ' Level failure rate in most rural secondary schools, which has generated criticisms leveled for the most part not against the examination system as an institution, but against what was deemed to be inadequate preparation of students by teachers for the examination. Goodson and Dowbiggin (1990: 108) say, "as passing examinations - particularly ' $O$ ' and 'A' Levels - is still closely tied to success" in Zimbabwe inordinate pressures are laid on the teaching community to maximize the chances of students making it". Now, given that the examinations and academic knowledge and skills are so closely connected-both because the most examinable subjects are infact the academic subjects, and because of the predominant weight of the examination in the assessment of such subjects, it is not surprising that students still value the academic as more important.

Goodson and Dowbiggin (1990:115) say, 
There is no available evidence on Zimbabwe to support observations made in Britain on the relationship between teachers' professional status, income and territoriality and the persistence of the reproduction of academic knowledge. But what was clear is that the genuine concern of teachers to see their students succeed a concern fuelled only in part by parental pressure, leads to a reinforcement of academic, and more specifically examinable knowledge as high status knowledge.

The above information clearly demonstrates that pressures from society and the examination system may influence the attitudes of teachers towards a certain model of curriculum. Teachers' perceptions towards a particular subject are very significant as evidence shows that they (teachers) have a very high probability of influencing pupils' attitudes either positively or negatively.

\section{CONClusion}

The paper concludes by arguing that attempts to introduce vocational education in the Zimbabwean secondary schools have largely just been "attempts". A number of variables have worked against the successful vocationalisation of the secondary school curriculum. First of all, the way how qualifications are recognized controlled and administered affected vocationalism. The stubborn persistence of academicism also stifled the implementation of the concept. It therefore became very clear that pressures from society and the examination system influenced the negative attitudes of stakeholders towards vocationalisation. Yet, evidence shows that the large numbers of school graduates leaving the education system who fail to secure job opportunities, can be helped by exposing them to a vocational based curriculum. An attempt at vocationalising the curriculum is actually trying to change the curriculum which has been in existence for many years which has produced most, if not all current leaders in business and education systems. This therefore means changing the mind sets of all these people.

\section{RECOMMENDATIONS}

In view of the findings and conclusions from the study, the researchers recommend the following:

A careful assessment of the existing curriculum is essential before any reform is undertaken, and must take into account the country's education policy and political, economic, demographic, cultural, social and technological environment. Problems to be solved, needs to be satisfied, and priorities to be addressed, must be identified, and recommendations made for action. Related matters such as access to learning, the extent of participation, retention, relevance, efficiency and the quality and effectiveness of programmes, and the provision of training, must also be considered. Major changes in the objectives, content and methods of teaching used in the curriculum should be reviewed, against the background of existing educational achievement and the constraints that have to be overcome. In the process of curriculum evaluation there are many questions to be asked. An important question is whether the support system was put in place for the implementation of the existing curriculum. If not, will it then be put in place for the revised curriculum? The challenges faced in the implementation of curriculum programmes vary from one country to another. In developing countries, however, many common issues are encountered. Among them are the following:

Focus on examinations: In many developing countries education is geared mainly to the passing of examinations on a narrowly selected number of subjects and competencies.

Poor achievement in examinations can lead to charges of inadequate curricula or incompetent teaching or both. Untrained teachers:

Those who teach are only as good as the training that they receive and use. Large numbers of teachers are ill prepared to deliver the curriculum.

Many classrooms have remained teacher centred and efforts to introduce a child-centered approach on a national scale have been fruitless. Social, economic considerations: In some countries the prevalence of unemployment is attributed to poor curricula.

In Zimbabwe, for example, as in many other counties, demands are made for curricula that will promote entrepreneurship and technical skills, and which enable school leavers to create employment for themselves, rather than become job seekers. 
Questions have been raised regarding the extent to which the school can adequately address technical skills development and whether school education should concentrate on the basic competencies needed for adult life. Such competencies would include, problem-solving, decision-making, analysis and communication skills, as well as those which are not trade specific, such' as designing and pattern-making, etc. Exposure to new technologies: These often serve to provoke and encourage curriculum reform, since school leavers often find that they need new skills and knowledge to live and work in the modem world.

\section{REFERENCES}

[1] Arnove, R. (1986). Educational revolution in Nicaragua. London: Praeger Press.

[2] Chung, F. and Ngara, I. (1985). Socialism, education and development: A challenge to Zimbabwe. Harare: Zimbabwe Publishing House.

[3] Goodson, I. and Dowbiggin, I. (1950). Curriculum history professionalization and the social organization of knowledge: An extended paradigm for the history of education. Oxford: Pergamon Press.

[4] Jansen, J. (1991). The state and the curriculum in the transition to socialism. The Zimbabwean experience. London: London Institute of Education.

[5] Naggard, R. (1989). The political and development implications of educational expansion with particular reference to Zimbabwe's secondary education sector. Manchester: University of Manchester.

[6] National Report of Zimbabwe (NRZ) (1988-90). Development of education "1980-90". Geneva: International Conference on Education.

[7] Swartz, L. (1992). Attempts to vocationalism in Zimbabwe. London: Plan.

[8] Sachikonye, L. (1990). Strains and stress in the Zimbabwe Education System: Interview with Fay Chung. Sheffield: Roape Publications.

[9] Siyakwazi, B. (1984). The philosophy of education with production in the Zimbabwean context. Bulletin of the University of Zimbabwe, 20 (3) 50-65.

[10] Treffgarne, C. (1989). Educational reforms in Zimbabwe. London: Institute of Education.

Citation: Wilard Nyathi, Caxton Shonhiwa. "Resistance of Vocationalism as Education for Entrepreneurship in the Secondary School System in Zimbabwe" International Journal of Humanities Social Sciences and Education (IJHSSE), vol 7, no. 10, 2020, pp. 59-64. doi: https://doi.org/10.20431/2349-0381.0710007.

Copyright: (C) 2020 Authors. This is an open-access article distributed under the terms of the Creative Commons Attribution License, which permits unrestricted use, distribution, and reproduction in any medium, provided the original author and source are credited. 